\title{
Diverticulum of a Meckel's diverticulum containing a stone
}

\author{
Eugene J. Gibney \\ Roscommon County Hospital, Roscommon, Ireland
}

\begin{abstract}
Summary: An 18 year old girl presented with acute abdominal pain and a calcified opacity in the pelvis. She proved to have a Meckel's diverticulum which had a secondary diverticulum at its apex, containing a stone. Meckel's stones are uncommon and diverticula of a Meckel's diverticulum exceedingly rare. This is only the second recorded case of such a diverticulum containing a stone, and the first to describe a calcified stone in this location.
\end{abstract}

\section{Introduction}

Although Meckel's diverticulum is one of the commonest congenital abnormalities of the gastrointestinal tract, it usually remains asymptomatic. When symptoms do develop, the diagnosis is seldom made preoperatively. However, enteroliths may rarely be found in a Meckel's diverticulum, ${ }^{1}$ although less than half of these are calcified and therefore visible on plain radiographs. ${ }^{2}$ This report describes a patient who presented with a symptomatic Meckel's diverticulum in whom a calcified enterolith was present in a secondary diverticulum at the apex of the Meckel's diverticulum.

\section{Case report}

An 18 year old girl was admitted with a 12-hour history of lower abdominal pain. This began and persisted in the suprapubic region, and was associated with nausea and vomiting. She had suffered from numerous bouts of similar pain in the preceding 2 years, and had been investigated 2 months prior to the present admission at another hospital where a gynaecological consultation and pelvic ultrasound had failed to reveal a cause for her symptoms. On examination she was apyrexial and had a normal pulse. Abdominal examination revealed moderate tenderness across the lower abdomen, but no guarding or rebound tenderness was present. Rectal and bimanual vaginal examination were both normal.

Correspondence: E.J. Gibney, F.R.C.S.I., 5 Copeland Grove, Clontarf, Dublin 3, Ireland.

Accepted: 28 February 1991
A plain abdominal $\mathrm{X}$-ray showed an unusual opacity projected just to the left of the midline in the pelvis (Figure 1). A laparotomy was performed the following day and the only abnormality found was a large broad based Meckel's diverticulum $(6 \times 3 \mathrm{~cm})$, at the apex of which was a secondary narrow-necked thin-walled diverticulum $(25 \mathrm{~mm}$ long) containing a calcified enterolith $(37 \times$ $23 \times 19 \mathrm{~mm}$ ) corresponding to the opacity seen on $\mathrm{X}$-ray. The segment of small bowel containing the? diverticulum was resected and an end-to-end anastomosis performed. She made an uncomplicated postoperative recovery. Pathological examination showed the diverticulum to be lined by small intestinal type mucosa without evidence of acute or chronic inflammation.

\section{Discussion}

Enteroliths in association with Meckel's diverticulum have been previously described but are rare. A recent report found that only 51 cases had been reported to date, ${ }^{3}$ and together with the present report and two additional cases not previously included, ${ }^{4,5}$ the total number of reported patients now stands at 54. In less than half of these cases have the stones been radiographically visualized. ${ }^{2,3}$

Most primary intestinal calculi form in areas of stasis, such as may occur in association with a stricture of the bowel (for example due to Crohn's disease or tuberculosis), a blind loop, or a diverticulum. ${ }^{6}$ Calcification is more likely to occur in the distal ileum because of a less efficient calcium transport and a higher $\mathrm{pH}^{7}{ }^{7}$ One of the characteristic radiological features of Meckel's stones is their mobility, demonstrated by their change in location 


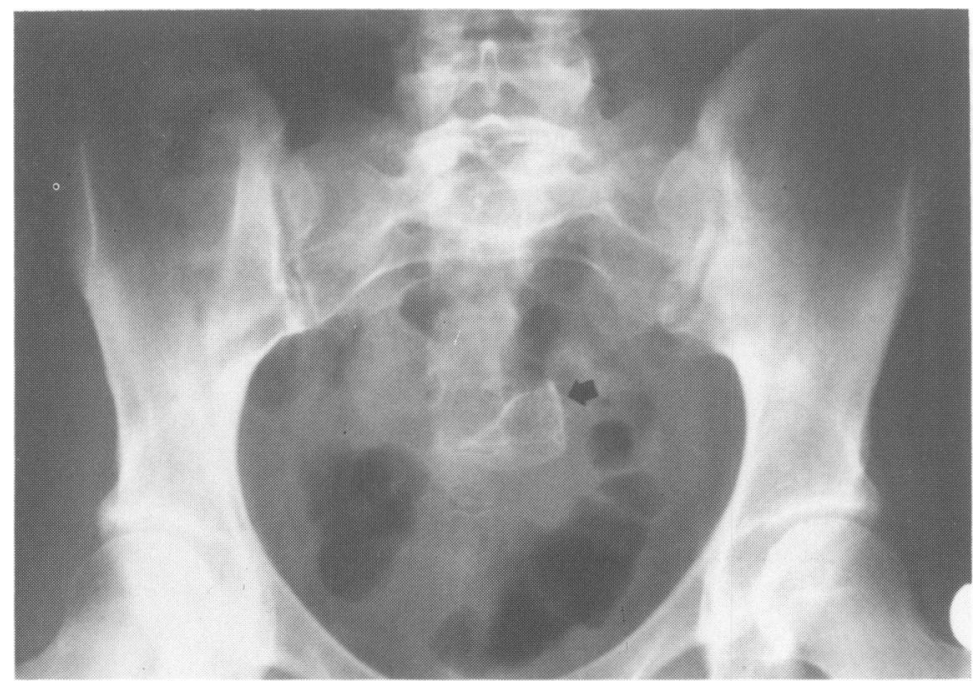

with the patient in different positions. ${ }^{8}$ This manoeuvre was not performed in our patient, but a repeat plain film 24 hours after the first showed the calcification to be in the same position. Meckel's stones may be misinterpreted as gallstones, ${ }^{9}$ teeth within a dermoid, ${ }^{10}$ or an appendiceal faecolith. ${ }^{8}$

Most Meckel's diverticula which contain stones are described as narrow-necked, ${ }^{5,10}$ and such a condition appears essential for the formation and retention of the stones. In the present case the Meckel's diverticulum was broad-based, but had, however, a secondary narrow-necked diverticulum at its apex in which the stone was found. The only other similar case was reported by Barr in $1984 .^{4}$ There is one report of a calcified enterolith developing in a persisting vitello-intestinal duct in association with a Meckel's diverticulum. ${ }^{11}$ There was, however, no connection between the umbilicus and the diverticulum in the present case. Secondary diverticula of Meckel's diverticulum are extremely rare, and are usually multiple. ${ }^{12,13}$ Their origin is probably embryological rather than hydrostatic. ${ }^{13}$

\section{References}

1. Sharma, G. \& Benson, C.K. Enteroliths in Meckel's diverticulum. Report of a case and review of the literature. Can J Surg 1970, 13: 54-58.

2. Kavlie, H. \& Marchioro, T.L. Calculi in a Meckel's diverticulum - a cause of chronic anaemia. Gastroenterology 1972, 62: $1238-1240$.

3. Hubens, G., Lamote, J. \& Willems, G. A stone in Meckel's diverticulum: a clue to its pre-operative diagnosis. Br J Clin Practice 1990, 44: 116-118.

4. Barr, H. Calculi in Meckel's diverticulum. Br J Surg 1984, 71: 478.
Not all Meckel's stones are associated with symptoms, but acute diverticulitis may occur. ${ }^{15}$ Enteroliths originating from a Meckel's diverticulum have also been associated with intestinal perforation. ${ }^{14}$ It seems likely that the Meckel's diverticulum (or rather its thin-walled secondary diverticulum) was responsible for the patient's symptoms in the present case because of the absence of any other apparent cause, and the relief of symptoms following resection. Since there was no histological evidence of inflammation, it is probable that the pain was due to intermittent obstruction of the smaller diverticulum by the stone.

This case report illustrates one of the few circumstances when a plain abdominal X-ray may provide a helpful clue to the diagnosis of Meckel's diverticulum, and describes, for the first time, a variant of this abnormality where a smaller secondary diverticulum at its apex contained a calcified enterolith.

5. Moran, K.T., McCormack, M. \& Flynn, J.R. Unusual presentation of a stone in a Meckel's diverticulum in association with acute appendicitis. Ir Med J 1985, 78: 320-321.

6. Atwell, J.D. \& Pollock, A.V. Intestinal calculi. Br J Surg 1960, 47: 367-374.

7. Singleton, J.McL. Calcific enterolith obstruction of the intestine. Br J Surg 1970, 57: 234-236.

8. Donner, M.W. \& Weiner, S. Diagnostic evaluation of abdominal calcifications in acute abdominal disorders. Radiol Clin North Am 1964, 2: 145-159. 
9. Harvey, I.C. \& White, H.J.O. Stones, Crohn's disease, and Meckel's diverticulum. Br Med J 1976, 4: 1107.

10. Ewing, H.P. \& Gear, M.W.L. Enteroliths in Meckel's diverticulum misinterpreted as teeth. Br J Surg 1984, 71: 157.

11. Harvey, C.F. \& Hood, J.M. Calcific enterolith in a vitellointestinal duct. $\mathrm{Br} J$ Surg 1984, 71: 316.

12. Bashline, D.L. \& White, B.J. Multiple diverticula of a Meckel's diverticulum. J Am Osteopath Assoc 1967, 66: 1391.
13. Kaneti, J. \& Mares, A.J. Diverticula of Meckel's diverticulum. Am J Surg 1975, 129: 597-598.

14. Guenier, C., Dryjski, J. \& Gouder, A. Perforation of the small intestine caused by an enterolith originating from a Meckel's diverticulum. Acta Chir Belg 1989, 89: 82-84. 